\title{
Approaches to participant recruitment and predictors of retention in a large community based public health trial: findings from the building blocks trial
}

\author{
Eleri Owen-Jones", Mike Robling, Julia Sanders, Rebecca Cannings-John, Gwenllian Moody \\ From 2nd Clinical Trials Methodology Conference: Methodology Matters \\ Edinburgh, UK. 18-19 November 2013
}

\section{Introduction}

Building Blocks is a randomised controlled trial evaluating the effectiveness of the Family Nurse Partnership (FNP) programme in 18 sites in England. FNP is a home visiting intervention aiming to address social exclusion and health disadvantage. Participants were 1600 teenage mothers, living in often challenging social circumstances. Recruitment usually followed an initial approach by a community midwife but also other local health or social care professionals.

\section{Methods}

Tailored recruitment pathways were established following a generic model whereby prospective participants completed a referral slip passed onto local Building Blocks researchers for subsequent approach. Explicit strategies for recruitment and retention were established, the latter in particular was developed in collaboration with the trial's lay stakeholder group. Potential predictors of successful follow-up (telephone and face-to-face interviews up to 24 months following birth) were explored using baseline data (e.g. socio-demographic, psychological, site characteristics).

\section{Results}

Recruitment rates varied considerably by site but with a small time extension exceeded the target. The success of various recruitment strategies will be assessed narratively and with reference to a theory of participation (Social Exchange Theory). Baseline factors found to be predictive of follow-up will be presented. In addition,

Cardiff University, Cardiff, Wales, UK

(C) 2013 Owen-Jones et al; licensee BioMed Central Ltd. This is an Open Access article distributed under the terms of the Creative Commons Attribution License (http://creativecommons.org/licenses/by/2.0), which permits unrestricted use, distribution, and reproduction in any medium, provided the original work is properly cited. simple logistical considerations (e.g. contemporaneous verification of contact details by local researchers) played a key role in managing follow-up.

\section{Discussion}

Our recruitment and retention strategies were informed by existing evidence, and were evaluated empirically and against contemporary theory of study participation. Understanding how evidence and theory may need to take into account specific trial circumstances will be explored in this presentation.

Published: 29 November 2013

doi:10.1186/1745-6215-14-S1-0111

Cite this article as: Owen-Jones et al:: Approaches to participant recruitment and predictors of retention in a large community based public health trial: findings from the building blocks trial. Trials 2013 14(Suppl 1):0111.

Submit your next manuscript to BioMed Central and take full advantage of:

- Convenient online submission

- Thorough peer review

- No space constraints or color figure charges

- Immediate publication on acceptance

- Inclusion in PubMed, CAS, Scopus and Google Scholar

- Research which is freely available for redistribution \\ () Biomed Central}

